\title{
Primerjalna književnost in antične študije: uvod v zgodovino ved in metodologije
}

Blaž Zabel

Univerza v Ljubljani, Filozofska fakulteta, Oddelek za filozofijo, Aškerčeva 2, 1000 Ljubljana https://orcid.org/0000-0001-6512-1565

blaz.zabel@ff.uni-lj.si

\begin{abstract}
Članek obravnava vprašanje recepcije antične književnosti vprimerjalni književnosti kot literarnovedni disciplini ter zgodovino odnosa med primerjalno književnostjo in antičnimi študijami. Zagovarja, da je odnos med obema vedama kompleksen in mnogoplasten, saj primerjalna književnost ks študiju antičnega izročila pogosto pristopa precej zadržano. Prispevek najprej obravnava vpliv antične književnosti in literarne kritike na razvoj zgodnje komparativistike $v$ Franciji. Pri tem opozori tudi na odklonilen odnos Antona Ocvirka do vloge antike v primerjalni književnosti. Nato prispevek razpravlja o dogajanjuv sodobnih antičnih študijah, pri čemer ugotavlja, da so metode primerjalne književnosti produktivno vplivale na metodološke premike. Izpostavlja predusem pluralizacijo koncepta antike v kontekstu postkolonialnih študij in študij svetovne književnosti ter razvoja recepcijskih študij antike. Vzaključku izpostavi, da sta imeli antična književnost in antične študije pomembno vlogo za razvoj komparativistike, po drugi strani pa je primerjalna književnost močno vplivala tudi na razvoj sodobnih antičnih študij.
\end{abstract}

Ključne besede: primerjalna književnost / antika / antična književnost / antične študije / literarna recepcija / Brunetière, Ferdinand / Texte, Joseph / Ocvirk, Anton / Wolf, Friedrich August

Namen te razprave je razmislek o odnosu, povezavah in razlikah med antično književnostjo, antičnimi študijami ${ }^{1}$ in komparativistiko. $\mathrm{Na}$ prvi pogled se ta tema morda zdi trivialna: antična književnost je od

${ }^{1}$ Izraz "antične študije« uporabljam kot prevod angleškega izraza "classics» (ali "classical studies«), včasih znan tudi kot klasične vede. Pri nas je splošno bolj uveljavljen izraz klasična filologija, ki pa je za namen te raziskave manj primeren, saj povečinoma pomeni preučevanje jezika in književnosti (prim. npr. uporabo izrazov v slovenski izdaji Kinney). Kot zagovarjam v tem članku, je prav interdisciplinarnost antičnih študij (ki poleg jezikoslovja in študija književnosti vključujejo še filozofijo, zgodovino, likovno umetnost itd.) ena najbolj produktivnih povezav s komparativistiko. 
vekomaj bila del svetovne književnosti in težko si predstavljamo komparativistiko brez preučevanja starogrških in latinskih literarnih del. Že Johann Wolfgang von Goethe (1749-1832) je o svetovni književnosti (Weltliteratur) razmišljal kot o literaturi, ki posnema in sledi starogrškemu literarnemu izročilu. $V$ znamenitih pogovorih z Johannom Petrom Eckermannom (1792-1854) najdemo naslednje razmišljanje:

Nacionalna literatura zdaj ne pomeni več veliko, na vrsti je doba svetovne literature in vsakdo mora prispevati, da se ta doba pospeši. Toda tudi spričo takega ocenjevanja tujega ne smemo obtičati pri čem posebnem in to vzeti za vzor. Ne smemo misliti, da je vzor kitajska ali srbska poezija ali Calderón ali Nibelungi. Če potrebujemo vzor, se moramo nenehno vračati k starim Grkom, saj je v njihovih delih vedno upodobljen lepi človek. Vse drugo moramo gledati zgolj historično in moramo si prisvojiti, kar je dobro, kolikor pač gre. (Eckermann, Pogovori 251) ${ }^{2}$

Po Goethejevem mnenju se svetovna književnost, ki je nadnacionalna in ni vezana zgolj na lokalen prostor, ne sme zavezati enemu samemu modelu, pa najsi bo ta še tako zanimiv, inovativen ali "svetoven«. Vzor naj pisatelju raje predstavlja starogrška književnost, ki je po svoji naravi nadčasovna ("vse drugo moramo gledati zgolj historično") in univerzalna (»v njihovih delih je vedno upodobljen lepi človek«). Z Goethejevim konceptom Weltliteratur so se sicer ukvarjali številni raziskovalci (prim. Juvan; Strich; Pizer; Moser), a na tem mestu želim poudariti, da je ideja svetovne književnosti močno zaznamovala razvoj komparativistike, številni pa Goetheja prištevajo kar med začetnike te discipline (prim. Birus; Damrosch, What is 1-36). V tem smislu so torej razmišljanja o antični književnosti zaznamovala primerjalno književnost že od njenih začetkov.

Pa vendar je odnos primerjalne književnost do antičnih študij in antike precej bolj kompleksen in dinamičen, kot se zdi na prvi pogled. Skupaj z Goethejem bi sicer lahko mislili, da antična književnost

\footnotetext{
${ }^{2}$ Vidmarjev prevod sem delno spremenil in ga dopolnil s prevodom v Virk 177. V nemščini se odlomek glasi: »Nationalliteratur will jetzt nicht viel sagen, die Epoche der Weltliteratur ist an der Zeit, und jeder muß jetzt dazu wirken, diese Epoche zu beschleunigen. Aber auch bei solcher Schätzung des Ausländischen dürfen wir nicht bei etwas Besonderem haften bleiben und dieses für musterhaft ansehen wollen. Wir müssen nicht denken, das Chinesische wäre es, oder das Serbische, oder Calderon, oder die Nibelungen sondern im Bedürfnis von etwas Musterhaftem müssen wir immer zu den alten Griechen zurückgehen, in deren Werken stets der schöne Mensch dargestellt ist. Alles übrige müssen wir nur historisch betrachten und das Gute, so weit es gehen will, uns daraus aneignen.« (Eckermann, Gespräche 198)
} 
zavzema posebno mesto $\mathrm{v}$ komparativističnih raziskavah, a nam različni pregledi te vede govorijo nasprotno. Tako David Damrosch v nedavni študiji Comparing the Literatures (2020) ugotavlja, da se primerjalna književnost in številne druge smeri literarne vede večinoma ukvarjajo zgolj s sodobnimi literarnimi tradicijami:

Ker pogosto raziskujem zgodnja obdobja, me skrbi, da se literarne vede vztrajno usmerjajo in močno osredotočajo na pretekli dve stoletji ali zgolj na zadnjih petdeset let - kar predstavlja le en odstotek vse pisne zgodovine. Vedno bolje znamo dekonstruirati rasizem, imperializem in v zadnjem času tudi specizem, vendar pa $\mathrm{v}$ našem delovanju večinoma povsem zanemarjamo preteči prezentizem; kljub temu, da je celo za razumevanje posledic sodobnih imperializmov, na primer, koristno, če se posvetimo številnim imperijem, ki so jim predhajali. (9)

Kot piše ameriški komparativist, se je iz starejših literarnih in kulturnozgodovinskih obdobij mogoče marsičesa naučiti, na primer glede sodobnih imperializmov; še več, starejše literarne tradicije celo vplivajo na naše razumevanje sodobnih literarnih del in na razumevanje današnjega časa. In vendar se literarna veda, še posebej pa primerjalna književnost, osredotočata povečini zgolj na literaturo zadnjih dveh stoletij ali zgolj zadnjih petdeset let. Antične književnosti, vsaj tako se zdi, ostajajo pozabljene ali pa se z njimi ukvarjajo specializirane vede, kot so na primer antične študije.

Že sama ambivalentnost med Goethejevo utemeljitvijo svetovne književnosti in Damroschevo analizo stanja sodobne literarne vede nam nalaga, da natančno premislimo o pomenu antične književnosti in antičnih študij za razvoj in stanje primerjalne književnosti kot literarnovedne discipline. $V$ prvem delu članka tako orišem nekatere glavne poglede primerjalne književnosti na antiko in na antično literarno izročilo ter razpravljam o tem, kako je starogrška in latinska književnost vplivala na razvoj komparativistike. Čeprav na kratko omenjam tudi delo Antona Ocvirka, se v svoji razpravi osredotočam predvsem na francosko primerjalno književnost, ki je močno zaznamovala razvoj te vede. Nato razpravljam o odnosu med komparativistiko in antičnimi študijami, predvsem o produktivnem vplivu primerjalne književnosti na razvoj preučevanja antike (ali bolje rečeno antik) v zadnjih petdesetih letih. Na koncu pa predstavim nekaj idej o tem, na kakšen način bi se lahko v prihodnje soočili z odnosom med komparativistiko, antičnimi študijami in starejšimi literarnimi tradicijami. 


\section{Rojstvo primerjalne književnosti iz duha antike}

Primerjalna književnost je razmeroma mlada literarnovedna disciplina, vsaj v primerjavi s klasično filologijo in antičnimi študijami. Pogosto se ta literarnovedna disciplina samo-opredeljuje kot primerjalno raziskovanje književnosti, kar ponavadi pomeni študij in primerjava literarnih del ali literarnih tradicij v več jezikih. $\mathrm{Na}$ takšen način so komparativistiko opredelili vsaj nekateri njeni predstavniki na samem začetku akademske institucionalizacije te vede; tudi zato, da se je lahko primerjalna književnost osamosvojila in otresla nadvlade nacionalnih literarnih ved. Primer takšne definicije je znamenito predavanje Ferdinanda Brunetièra (1849-1906) z naslovom "La littérature europèene«, ki ga je francoski akademik predstavil na pariškem kongresu leta 1900. V svojem prispevku "primerjalno literarno zgodovino odločno zoperstavi folkloristiki in jo opredeli kot primerjalno raziskovanje novoveške beletristike v sodobnih evropskih jezikih. Novoveška evropska književnost po letu 1500, kot pravi Brunetière, tvori zgodovinsko in odnosno povezan in enovit sistem, zato je le-ta najprimernejša za primerjalno raziskovanje. Antične književnosti - in pri tem je treba opozoriti, da je francoski komparativist jasno prepoznal pluralnost in večkulturnost antičnih tradicij ${ }^{3}-\mathrm{v}$ primerjalni literarni zgodovini nimajo svojega mesta, saj niso del tega novoveškega in evropskega literarnega sistema. Takole namreč pravi Brunetière:

Bolj zahtevno pa je vprašanje, ali naj opredelitev primerjalne književnosti zajame tudi pesmi Du Fuja in Li Baija kakor tudi Sapfo in Pindarja. [...] Te oddaljene in skrivnostne civilizacije so se razvile izven naše civilizacije in so zato imele malo stikov. Ponujajo torej priložnostne podobnosti in sovpadanja, a malo primerjav. Isto velja za književnosti. V nekem smislu je poezija $\mathrm{Du}$ Fuja in Li Baija podobna Anakreontu in Horaciju, Parnyu in Bérangerju [...]. Vendar po drugi strani zlahka opazimo bistvo težave, če je kot pogoj oziroma za resnično plodno primerjavo potrebna določena stalnost komunikacije ali izmenjav, pa tudi vzajemnost, izvor ali sorodstvo med objekti primerjanja. (Brunetière 327)

${ }^{3}$ Poleg latinsko-grške književnosti Brunetière med drugim omenja še starokitajsko, staroindijsko, hebrejsko, arabsko, perzijsko in hindujsko književnost. Čeprav lahko vse te književnosti razumemo kot "antične«, v smislu da so zgodovinsko predhajale modernim literarnim tradicijam, je treba poudariti, da je njihova "antičnost" zgodovinsko neenotna in se razprostira preko več kot tisoč let. Prav ta zgodovinska nepovezanost je verjetno razlog, zakaj se je Brunetière odrekel primerjavam različnih antičnih literarnih del. 
Ne zgolj, da je zaradi umanjkanja "komunikacije» in "vzajemnosti" nemogoče primerjati oddaljene literarne tradicije (kot bi bila na primer primerjava starokitajske in starogrške poezije), temveč je za komparativistično preučevanje najprimernejša evropska književnost nekje po času iznajdbe tiska, ki je šele zares omogočil to »stalnost komunikacije«. Nobenega dvoma ni, saj je glede tega Brunetière jasen, da je antična (torej starogrška in latinska) književnost vplivala na razvoj evropske književnosti, vendar pa se pravi komparativistični projekt začne šele $s$ časom renesanse. V zgornjem Brunetièrovem opisu je tako mogoče prepoznati začetek kontinuirane usmerjenosti na sodobno literarno produkcijo, ki jo komparativistiki očita tudi Damrosch.

Vendar pa je slika, ki se skriva v ozadju preferiranja sodobnih literarnih tradicij pred antiko, bolj dinamična in kompleksna, kot se kaže v zgornjem opisu. Čeprav so starejše literature v primerjalni književnosti bile in še vedno so potisnjene v ozadje (ali pa vsaj niso primarni predmet raziskovanja), je bila latinsko-grška antika v simbolnem, ideološkem, pa tudi v metodološkem smislu vseskozi prisotna. To je razvidno že $\mathrm{v}$ Brunetièrovi opredelitvi primerjalne literarne zgodovine, kjer je antičnemu in srednjeveškemu literarnemu izročilu vendarle pripisan določen pomen, in sicer v recepciji s strani sodobnih, nacionalnih literatur:

Hkrati [...] bi opozorili na eno najzanimivejših stališč, s katerega lahko obravnavamo zgodovino 'evropske književnosti'. Se pravi, izvedeti, kaj se je zgodilo $\mathrm{z}$ izvirno temo, enako po svojem izvoru in pomenu, kaj se je zgodilo z epsko ali dramsko temo, ko je prehajala iz enega miljeja $v$ drugega, ali pa se je nacionalizirala znotraj različnih meja; rečeno natančneje, kaj se je zgodilo z evropsko [temo] ko je postala španska, recimo, ali pa francoska. (Brunetière 338; poudarki so v izvirniku)

Za francoskega raziskovalca je najzanimivejše vprašanje, ki si ga o antiki in srednjem veku lahko zastavi komparativist, vprašanje o tem, kako je kozmopolitska in ne-nacionalna antična književnosti ${ }^{4}$ vplivala na novoveško in nacionalno književnost (torej na špansko, francosko itd.). Kot bomo videli v drugem delu tega članka, je preučevanje recepcije antike danes postalo pomembna smer antičnih študij, njene začetke pa lahko prepoznamo že v idejah in zanimanjih zgodnjih komparativistov.

${ }^{4}$ Tukaj se odpira tudi prostor za premislek o Brunetièrovem razumevanju antične književnosti kot »evropske«, kar so v današnjem času pod vprašaj postavili številni preučevalci antične književnosti. Glej predvsem spodnjo razpravo o postkolonialni teoriji v antičnih študijah. 
Pomen antike za razvoj komparativistike se ne skriva zgolj v vplivu antičnih motivov in zvrsti na sodobno književnost, temveč so številni komparativisti (načrtno ali nevede) svoje razumevanje »literarnega primerjanja" oblikovali na podlagi starejše tradicije primerjanja starogrške in latinske književnosti, ki se je začela že v antiki. Primerjanje teh antičnih tradicij, vključno $s$ preučevanjem različnih literarnih vplivov, torej predstavlja metodološki temelj, iz katerega je v svojih začetkih črpala primerjalna književnost. To lahko vidimo, na primer, v znameniti opredelitvi te vede, ki jo je v svojem delu La littérature comparée (1931) podal francoski komparativist Paul van Tieghem (1871-1948):

Kot smo že omenili, je namen primerjalne književnosti v bistvu preučevanje del različnih [nacionalnih] literatur v njihovem medsebojnem razmerju, kar obsega razmerje med grško in latinsko književnostjo, dolg sodobne književnosti (tiste po srednjem veku) antični književnosti in povezave med različnimi sodobnimi književnostmi. (33)

Kot sem opozoril že pri Brunetièru, je recepcija antične literature s strani sodobnih literarnih tradicij - kot zapiše van Tieghem, »dolg sodobne književnosti (tiste po srednjem veku) antični književnosti« - eden izmed pomembnih vidikov zgodnje komparativistike. Drugi pomemben moment pa se skriva $v$ dejstvu, da je sama ideja literarne primerjave močno zaznamovana $\mathrm{z}$ dolgo tradicijo primerjanja starogrške in latinske književnosti. Kot pravi van Tieghem, je naloga komparativistike preučevati »razmerje med grško in latinsko književnostjo «; vendar pa to ni zgolj ena izmed nalog komparativistike, temveč obenem predstavlja zgodovinski in metodološki vir samega literarnega primerjanja.

Da je ideja primerjanja starogrške in latinske književnosti močno zaznamovala sam koncept komparativistike, je mogoče prepoznati tudi v drugi znameniti opredelitvi te vede, ki jo je v uvodu v La Littérature Comparée: Essai Bibliographique (1900) podal eden izmed očetov komparativistike Joseph Texte (1865-1900). V uvodu v bibliografski kompendij, ki ga je sestavil Louis-Paul Betz (1861-1904), je namreč zapisal sledeče:

Primerjalna zgodovina literature resnici na ljubo ni novost, niti ni res, da bi se šele danes ali včeraj zavedli potrebe po takšnih raziskavah. Prej obratno, rečemo lahko, da je bila primerjalna metoda že stoletja najpomembnejša metoda literarne zgodovine. Tako je bilo še zlasti $\mathrm{v}$ antiki, $\mathrm{v}$ renesansi, v klasicističnem obdobju večine modernih literatur. $\mathrm{V}$ antiki je bila prav primerjava latinskih del z njihovimi grškimi izvirniki osnova [literarne] kritike: kaj dolguje Terencij Menandru? Vergilij Homerju? Ciceron Panetiju? Lukrecij 
Epikurju? Niso to vprašanja, ki so si jih nenehno zastavljali najslavnejši antični kritiki od Horacija do Kvintilijana? In ali ni zgodovina rimske književnosti v nekem smislu nič drugega kot dolgo vzporejanje latinske in grške genialnosti? (Texte xix)

Jasno je torej, da so se zgodnji komparativisti zavedali svojega dolga antični književnosti in antični literarni kritiki. Ideja literarnega primerjanja, ki so jo prevzeli, je torej izvirala iz antike, čeprav so jo raziskovalci večinoma aplicirali izključno na primerjanje modernih literarnih del in tradicij, torej na primerjanje nacionalnih evropskih književnosti.

Preden zaključim razpravo vpliva antike in antične literarne kritike na razvoj primerjalne književnosti, velja na kratko omeniti še vprašanje slovenske komparativistike. Žal pri nas še nihče ni opravil sistematične razprave o tem, kakšno vlogo je antična književnost imela za razvoj primerjalne književnosti v našem akademskem prostoru. Čeprav je zgodovina komparativistike v Sloveniji dobro raziskano področje, se zdi, da je imelo preučevanje antične književnosti poseben status. Kot primer svojevrstnega pristopa do antične tradicije lahko navedem Antona Ocvirka (1907-1980) in njegovo razumevanje te literarnovedne discipline. Poglejmo si, na primer, Ocvirkovo reinterpretacijo zgornje Textove definicije komparativistike, ki jo je oče slovenske primerjalne književnosti podal v Teoriji primerjalne literarne zgodovine (1936). Ocvirk o komparativistiki in antični književnosti zapiše sledeče:

Svoja znanstvena načela je primerjalna literarna zgodovina dodobra opredelila šele ob koncu minulega stoletja, metodološko pa je vsestransko zarisala svoje področje komaj v zadnjih desetletjih. Vendar ima nova veda obsežnejšo preteklost, saj zasledimo početke primerjalne usmerjenosti že $\mathrm{v}$ prejšnjih stoletjih. Prvotnemu ukvarjanju s paralelizmi je sledilo globlje zanimanje za posebnosti raznih književnosti in njihove medsebojne odnose, ki si je polagoma izoblikovalo trdnejše literarnozgodovinske temelje ter se tudi teoretično zasidralo. Te prve stopnje $\mathrm{v}$ razvoju primerjalne znanosti nikakor ne smemo prezreti, ker nam razjasnjuje vire, iz katerih je nastala, in kaže probleme, kakor so se časovno vrstili.

Ni dvoma, da je že antika poznala literarno vzporejanje, a ga je uporabljala le v kritične namene, da bi ugotovila vsebinsko ali pa snovno odvisnost latinskih pisateljev od grških. Primerjanje Vergila s Homerjem, Akcija s Sofoklejem, Terenca z Menandrom ali Cicerona z Demostenom ni imelo literarnozgodovinske podlage, zato ne spada $\mathrm{v}$ okvir primerjalne literature, kakor jo pojmujemo danes. Povsem nepravilno bi bilo torej, če bi morda menili, da so bile že v antiki prve kali primerjalne vede. (Ocvirk $\$ 8-90)^{5}$

\footnotetext{
${ }^{5}$ Navedeno po drugi, spletni izdaji (glej Ocvirk).
} 
$\mathrm{V}$ tem Ocvirkovem razmišljanju zasledimo zanimivo kombinacijo zgoraj predstavljenih tez. Omemba primerjave "Vergila s Homerjem" in »Terenca z Menandrom" je že kar intertekstualno spogledovanje s Textovim iskanjem izvora primerjalne književnosti - le da je Ocvirk potegnil nekoliko drugačne zaključke in zapisal, da bi bilo "povsem nepravilno«, če bi začetke primerjalne vede iskali v antiki. V tem pogledu je torej Ocvirk bližje Brunetièru, saj mu je za oblikovanje svojega »komparativističnega" projekta bolj koristilo zanikanje antične tradicije kot pa aktivno spopadanje z vplivom antičnih literatur na razvoj primerjalne književnosti (čeprav je treba dodati, da je Ocvirk govoril o primerjalni literarni zgodovini, antične primerjave literarnih del pa niso nastale iz koncepta zgodovinske spremenljivosti). A kot sem zapisal že zgoraj, bi bilo za natančno razumevanje vloge antike za razvoj primerjalne književnosti pri nas potrebno opraviti podrobnejšo raziskavo.

\section{Primerjalna književnost in antične študije}

V prvem delu sem na kratko spregovoril o razvoju primerjalne književnosti in odnosu te literarnovedne discipline do antike. Vendar pa komparativistika ni zgolj preučevala antike oziroma gradila na njenih predstavah, temveč je zajemala tudi pri samih antičnih študijah - in kot bomo videli, nanje tudi vplivala. Če sem zgornjo razpravo začel z nekaterimi definicijami začetnikov komparativistike, bi na tem mestu predstavil, kako literarno raziskovanje opredeli eden izmed zgodnjih filologov, Friedrich August Wolf (1759-1824). Wolf, ki velja za utemeljitelja antičnih študij in je bil eden izmed izumiteljev tekstne kritike, je namreč leta 1807 izdal spis z naslovom Darstellung der Alterthumswissenschaft, v katerem je antične študije tudi programsko opredelil. Tukaj navajam Wolfovo osebno beležko, ki mu je služila kot priprava za pisanje tega programskega spisa:

$\mathrm{Z}$ antično književnostjo pojmujemo tiste veje vednosti, ki nas seznanijo s celotno politično, intelektualno in gospodarsko strukturo in kulturo prebivalcev antike, zlasti obeh ljudstev v antiki [t.j. starih Grkov in Rimljanov], z njihovimi jeziki, umetnostjo, znanostjo, manirami, značajem in načinom razmišljanja... (Markner in Veltri 51) ${ }^{6}$

Vsak preučevalec antike ve, da so antične študije v svoji osnovi interdisciplinarna veda, saj preučujejo več vidikov starogrške in latinske kulture: ne zgolj jezika in književnosti, ampak tudi likovno umetnost,

\footnotetext{
${ }^{6}$ Za podrobnejšo analizo tega zapisa glej Harloe 197-202.
} 
arheologijo, zgodovino, antično filozofijo, antično znanost itd. Vsi ti vidiki so neločljivo povezani, zato težko razumemo en modus antične kulture brez upoštevanja drugih vidikov. Kot primer lahko navedem književnost: določenega literarnega dela namreč ni mogoče interpretirati brez upoštevanje zgodovinskega, filozofskega, arheološkega in splošnokulturnega konteksta.

Iz vidika interdisciplinarnosti so torej antične študije (oziroma Altertumswissenschaft) po svoji naravi primerjalne, saj morajo z literarnimi teksti primerjati vsaj njihov zgodovinski, filozofski in širši kulturni kontekst antičnih družb. Poleg tega, seveda, kar je bilo rečeno že zgoraj, in sicer da antične študije med seboj primerjajo starogrško in latinsko literarno izročilo, pa tudi likovno umetnost, filozofijo, glasbo itd. Antične študije so torej v svoji osnovi podobne primerjalni književnosti, vsaj v kolikor sledimo eni izmed najpogosteje navajanih modernih definicij, ki jo je predlagal Henry H. H. Remak:

Primerjalna književnost je študij književnosti izven meja ene same države ter študij odnosov med literaturo na eni strani in drugimi področji znanj ter prepričanj, kot na primer likovna umetnost itd. Povedano na kratko, [primerjalna književnost] je primerjava ene književnosti z drugo [književnostjo] ali drugimi [književnostmi] in hkrati primerjava književnosti z drugimi področji človekovega izražanja. (Remak 3)

V skladu z Remakovo opredelitvijo, ki odslikava interdisciplinarnost razvoja te vede $\mathrm{v}$ ameriškem povojnem obdobju, se primerjalna književnost ukvarja s primerjanjem različnih literatur in literarnih tradicij ter $s$ primerjanjem književnosti z drugimi področji človekovega izražanja, kot na primer z likovno umetnostjo, glasbo, filozofijo, filmom itd. V tem smislu je predmet njenih primerjav soroden antičnim študijam, saj se tudi slednje ukvarjajo s primerjavami starogrške in latinske književnosti ter $s$ primerjavo literature in drugih področij, kot so likovna umetnost, filozofija, zgodovina itd. In kot sem poudaril že v zgornji obravnavi programskega spisa Friedricha Augusta Wolfa, so bile antične študije na tak način zasnovane že od samega začetka.

Čeprav med primerjalno književnostjo in antičnimi študijami obstaja kar nekaj metodoloških podobnosti, kar nakazuje na to, da se je komparativistika razvijala tudi pod vplivom klasične filologije, pa je potrebno izpostaviti še, da $\mathrm{v}$ zadnji petdesetih letih tudi preučevalci antike (klasični filologi) pogosto posegajo po sodobnih komparativističnih pristopih in metodah. Tako je primerjalna književnost $\mathrm{v}$ več pogledih vplivala na nekatere temeljne disciplinarne in metodološke premike $v$ antičnih študijah. Tukaj naj omenim zgolj dva primera. Prvi primer je 
pluralizacija termina antika, ki je neposreden odziv na dogajanje v komparativistiki, predvsem na postkolonialno teorijo in na študije svetovne književnosti. Ko je v sedemdesetih, osemdesetih in kasneje kritična teorija v komparativistiki pod vprašaj postavila zahodni kanon kot glavni nabor besedil, ki se jim posveča primerjalna književnost, so se te debate postopoma prenesle tudi v antične študije. Tako se se tudi klasični filologi začeli spraševati, ali lahko govorimo zgolj o latinsko-grški antiki, ali pa je treba upoštevati tudi druge stare kulture.

S tega vidika je najprelomnejše delo Black Athena Martina Bernala, ki je izšla leta 1987. V njej Bernal zagovarja tezo, da je zahodna tradicija načrtno zanemarila in spregledala vpliv antičnega Egipta ter Levanta na razvoj starogrške kulture. In čeprav je s filološkega vidika Black Athena (predvsem pa njen drugi in tretji del, ki sta izšla leta 1991 in 2006 in sta posvečena vprašanjem zgodovine, arheologije in jezikoslovja) manj prepričljiva, je na široko odprla vrata različnim raziskavam medkulturnega transferja in medkulturnih literarnih vplivov v antiki. Med najpomembnejše raziskovalce tega področja sodita Martin L. West s svojo vplivno študijo The East Face of Helicon (1997) in Walter Burkert z The Orientalizing Revolution (1992), oba pa sta pokazala, da je bila starogrška književnost $\mathrm{v}$ stiku in pod vplivom bližnjevzhodnih literarnih tradicij. Zanimivo je, da je West svojo študijo oblikoval po vzoru klasične komparativistične raziskave, kot jo je predlagal na primer Paul van Tieghem. Van Tieghem je namreč razdelil komparativistično raziskovanje na tri glavna področja: doksologijo (ki preučuje vpliv nekega dela ali tradicije na druge tradicije), krenologijo (ki preučuje tuje vplive na neko delo ali tradicijo) in mezologijo (ki preučuje literarne posrednike). West v svoji študiji prav tako obravnava vse tri vidike: preučuje vpliv akadske književnosti na starogrško, analizira bližnjevzhodne vire v delih arhaične dobe (Heziod, Homer, liriki, Ajshil), na koncu pa razpravlja še o možnih medkulturnih prenosih, torej o literarnih posrednikih. Tako West kot Burkert sta torej filološko utemeljila to, kar je predlagal že Bernal, da torej starogrška književnost ni nastala v vakumu, temveč so nanjo vplivale druge antične kulture.

Pluralizacija termina antika, ki ga danes pogosto zapisujemo v množini, torej antike, je v zadnjih dve desetletjih dobila nov komparativističen zagon, predvsem pod vplivom diskusij o svetovni književnosti. Tako sta na primer Wiebke Denecke in Alexander Beecroft pokazala, da lahko latinsko-grško antiko zelo produktivno primerjamo s starokitajsko in starojaponsko literarno tradicijo (Denecke; Beecroft, Authorship; Beecroft, An Ecology). Spet drugi so pokazali na produktivnost primerjav z nekaterimi drugimi antičnimi literaturami, na primer, staroindij- 
sko književnostjo, staroarabsko književnostjo, staroperzijsko literarno tradicijo itd. Antične študije so torej v zadnjem času prav pod vplivom komparativistike relativizirale svoje razumevanje antike, $s$ pomočjo komparativistične metodologije pa so v svoj raziskovalni spekter pritegnile številne druge antične tradicije.

Drugi primer produktivnega vpliva komparativistike na antične študije pa je razvoj tako imenovanih recepcijskih študij antike (angl. classical reception studies; prim. Zabel 211). Recepcijske študije antike se ukvarjajo z recepcijo antične literature, umetnosti in kulture $s$ strani kasnejših (primarno novoveških) literarnih tradicij in drugih umetnostnih zvrsti, na primer, filma, glasbe, gledališča, fotografije itd. Med začetnike recepcijiskih študij antike lahko štejemo Charlesa Martindalea, ki je v svojem delu Redeeming the Text: Latin Poetry and the Hermeneutics of Reception (1992) pokazal, da je v današnjem času nemogoče govoriti o antični književnosti brez upoštevanje njene recepcijske zgodovine. Antika se je namreč neprestano opomenjala preko številnih literarnih interpretacij in reinterpretacij, tako da je do izvirne interpretacije antičnih literarnih del nemogoče dostopati. Kot predlaga Martindale, se mora torej fokus raziskovanja antike usmeriti tudi na samo recepcijsko zgodovino, torej na preučevanje interpretacije in umetniškega odziva v post-antičnih obdobjih. Metodološke začetke študija recepcije lahko seveda najdemo $\mathrm{v}$ temeljnih delih nekaterih komparativistov in hermenevtov, predvsem pa v delu Hansa Roberta Jaussa, ki je "recepcijo" filozofsko utemeljil (v delu Estetsko izkustvo in literarna hermenevtika iz leta 1982). Charles Martindale je v svoji študiji jasno prepoznal pomen Jaussovega dela za preučevanje antike (manj pa svoj metodološki dolg sami primerjalni književnosti), s čimer je sprožil pravo revolucijo v klasičnih študijah, ki danes recepcijo antike priznavajo kot eno svojih temeljnih področij raziskovanja.

\section{Vloga antičnih literatur v komparativistiki}

$\mathrm{V}$ prvem in drugem delu tega članka sem predstavil kompleksnost odnosa med primerjalno književnostjo, antično književnostjo in antičnimi študijami. Za odnos primerjalne književnosti do antike se zdi, da je bil do določene mere odklonilen, a sem $\mathrm{z}$ analizo nekaterih temeljnih komparativističnih del in metodologij pokazal, da so antična književnost, antična tradicija in antične študije produktivno vplivale na razvoj primerjalne književnost. Kot sem torej dokazoval, je bila antična književnost ključna za razumevanje nekaterih temeljnih komparativističnih 
vprašanj; prav tako pa sta bili antične študije in primerjalna književnost kot dve literarnovedni disciplini med seboj v neprekinjenem dialogu že od njunega nastanka. $\mathrm{Ob}$ tem sem posebej poudaril, da je mogoče inovativne pristope $\mathrm{k}$ preučevanju antike poiskati v metodologijah primerjalne književnosti, da je primerjalna metoda ključna za celovito razumevanje antične književnosti in da lahko komparativistika pomaga pri razumevanju antike kot večkulturnega fenomena.

$\mathrm{Na}$ podlagi zgoraj izvedene analize lahko torej oblikujem sledeče zaključke. Prvič, da sta bili antična književnost in antična literarna kritika ključni za razvoj primerjalne književnosti kot literarnovedne discipline, pa čeprav je komparativistika poskušala ta vpliv pogosto zakriti in se je predstavljala kot študij novoveške beletristike ali nacionalnih literarnih tradicij. Antika je torej predstavljala idejni in metodološki temelj, na podlagi katerega se je v svojih začetkih samo-opredeljevala primerjalna književnost. V tem smislu sta antika in antična književnosti imeli pomemben vpliv na razvoj komparativistike.

Drugič, na razvoj primerjalne književnosti ni vplivala zgolj antična književnost, ampak tudi antične študije. Kot sem pokazal, so antične študije v svoji programski zasnovi sorodne primerjalni književnost (vsaj kot jo razumemo od druge svetovne vojne dalje). Oče antičnih študij, Friedrich August Wolf, je disciplino utemeljil kot študij antične literature, umetnosti, zgodovine, filozofije itd., za katero je primerjalno raziskovanje bistvenega pomena. Podobno pa tudi danes komparativistiko lahko opredelimo kot študij različnih (nacionalnih) književnosti ter študij odnosa med književnostjo in filozofijo, likovno umetnostjo, glasbo itd. Vsaj z metodološkega vidika sta torej obe disciplini komparativistični, pri čemer je razvoj komparativizma $\mathrm{v}$ antičnih študijah mogoče zaslediti že v poznem 18. in zgodnjem 19. stoletju.

Tretjič, da je primerjalna književnost prav tako vplivala na razvoj metodologij v antičnih študijah. V članku sem ugotavljal, da so bile raziskave v primerjalni književnosti ključne za pluralizacijo in večkulturnost razumevanja antike in za razvoj recepcijskih študij antike kot ene izmed najvidnejših in najpomembnejših sodobnih usmeritev te vede - kar sem pokazal na primeru postkolonialne teorije, študija svetovne književnosti in recepcijske teorije Hansa Roberta Jaussa. A lahko bi našteli še več drugih metod in teorij primerjalne književnosti, ki so vplivale na razvoj antičnih študij, kot so na primer naratologija, digitalna humanistika, teorija traume, ekokritika etc. Iz zgoraj povedanega je torej jasno, da je primerjalna književnost vplivala na razvoj antičnih študij.

Četrtič, na osnovi zapisanega v zgornjih treh točkah, lahko ugotovimo tudi, da sta se obe disciplini skozi čas razvijali v skupnem dialogu in med- 
sebojenem oplajanju. Če se je primerjalna književnost razvila in vsaj na začetku samo-opredeljevala tudi pod vplivom antične tradicije, antične literarne kritike in samih antičnih študij, je prav tako mogoče govoriti o vplivu primerjalne književnosti na metode in področja raziskovanja antičnih študij. Obe literarnovedni disciplini se torej že od samih začetkov medsebojno bogatita in ena na drugo produktivno vplivata.

In petič, zaključim lahko, da je za temeljito komparativistično raziskovanje ter za razumevanje književnosti (tudi sodobne književnosti) nujno upoštevati starejše literarne tradicije, ki so zaznamovale in sooblikovale koncepte, metodologije in različne uveljavljene interpretacije literarnega raziskovanja. Če je namreč antika vplivala na razvoj primerjalne književnosti in njene metodologije, je težko razumeti samo vedo, brez upoštevanja vloge antične tradicije za njen razvoj. In nadalje, če so antične književnosti bistveno sooblikovale sodobne literarnovedne koncepte in poglede, se zdi pomembno in koristno, da pri preučevanju književnosti (oziroma katerekoli literararne tradicije) upoštevamo tudi starejšo, predmoderno književnost. Na neki način je raziskava $\mathrm{v}$ tem članku pokazala podobno, kar je na samem začetku trdil že David Damrosch, namreč, da je koristno, če se pri preučevanju sodobnih literarnovednih vprašanj posvetimo tudi literaturam, obdobjem in vprašanjem, ki so jim predhajali.

\section{LITERATURA}

Beecroft, Alexander. Authorship and Cultural Identity in Early Greece and China. Patterns of Literary Circulation. Cambridge: Cambridge University Press, 2010.

Beecroft, Alexander. An Ecology of World Literature. From Antiquity to the Present Day. London; New York, NY: Verso Books, 2015.

Bernal, Martin. Black Athena. The Afroasiatic Roots of Classical Civilization. Vol. 1. The fabrication of Ancient Greece 1785-1985. New Brunswick, NJ; London: Rutgers University Press; Free Association Books, 1987.

Betz, Louis-Paul. La littérature comparée. Essai bibliographique. Strasbourg: Karl J. Trübner, 1900.

Birus, Hendrik. "The Goethean concept of world literature and comparative literature«. CLCWeb: Comparative Literature and Culture 2.4 (2000). Splet. 26. 5. 2021. <https://doi.org/10.7771/1481-4374.1090>

Brunetière, Ferdinand. "La littérature Européenne«. Revue des deux mondes 46.9 (1900): 276-355.

Burkert, Walter. The Orientalizing Revolution. Near Eastern Influence on Greek Culture in the Early Archaic Age. Cambridge, MA; London: Harvard University Press, 1992.

Damrosch, David. What is World Literature? Princeton, NJ: Princeton University Press, 2003.

Damrosch, David. Comparing the Literatures. Literary Studies in a Global Age. Princeton, NJ: Princeton University Press, 2020. 
Denecke, Wiebke. Classical World Literatures. Sino-Japanese and Greco-Roman Comparisons. Oxford; New York, NY: Oxford University Press, 2014.

Eckermann, Johann Peter. Gespräche mit Goethe in den letzten Jahren seines Lebens. Ur. Regine Otto in Otto Wersig. München: Beck, 1988.

Eckermann, Johann Peter. Pogovori z Goethejem. Prev. Josip Vidmar. Ljubljana: Cankarjeva založba, 1959.

Harloe, Katherine. Winckelmann and the Invention of Antiquity. History and Aesthetics in the Age of Altertumswissenschaft. Oxford: Oxford University Press, 2013.

Jauss, Hans Robert. Estetsko izkustvo in literarna hermenevtika. Prev. Tomo Virk. Ljubljana: LUD Literatura, 1998.

Juvan, Marko. Prešernovska struktura in svetovni literarni sistem. Ljubljana: LUD Literatura, 2012.

Kinney, Liam. Dvanajst razlogov za študij klasične filologije v enaindvajsetem stoletju. Prev. Matej Hriberšek, Andreja Inkret, Jerneja Kavčič, David Movrin, Zala Rott, Brane Senegačnik in Sonja Weiss. Ljubljana: Znanstvena založba Filozofske fakultete v Ljubljani, 2018.

Markner, Reinhard, in Giuseppe Veltri, ur. Friedrich August Wolf. Studien, Dokumente, Bibliographie. Stuttgart: Franz Steiner Verlag, 1999.

Martindale, Charles. Redeeming the Text. Latin Poetry and the Hermeneutics of Reception. Cambridge: Cambridge University Press, 1993.

Moser, Christian. »From literary predation to global intellectual commerce: world literature, world history, and the modes of cultural exchange in the work of Johann Gottfried Herder and Johann Wolfgang Goethe«. The Routledge Companion to World Literature and World History. Ur. May Hawas. Abingdon; New York, NY: Routledge, 2018.

Ocvirk, Anton. Teorija primerjalne literarne zgodovine (1936). 2. izd. Prva elektronska izdaja. Ur. Luka Vidmar in Matija Ogrin. Ljubljana: Inštitut za slovensko literaturo in literarne vede ZRC SAZU, 2010. Splet. 26. 5. 2021. <http://nl.ijs.si:8080/ fedora/get/ezmono:tplz/VIEW/>

Pizer, John David. The Idea of World Literature. History and Pedagogical Practice. Baton Rouge, LA: Louisiana State University Press, 2006.

Remak, Henry H. H. "Comparative literature: its definition and function". Comparative Literature. Method and Perspective. Ur. Newton Phelps Stallknecht in Horst Frenz. Carbondale, IL: Southern Illinois University Press, 1971. 3-57.

Strich, Fritz. Goethe und die Weltliteratur. Bern: Francke Verlag, 1946.

Texte, Joseph. "Introduction«. La littérature comparée. Essai bibliographique. Avtor Louis-Paul Betz. Strasbourg: Karl J. Trübner, 1900. xix-xxiv.

Van Tieghem, Paul. La littérature comparée. Paris: A. Colin, 1931.

Virk, Tomo. Primerjalna književnost na prelomu tisočletja. Ljubljana: ZRC SAZU, 2007.

West, Martin L. The East Face of Helicon. West Asiatic Elements in Greek Poetry and Myth. Oxford, New York, NY: Clarendon Press, 1997.

Zabel, Blaž. "Prihodnost klasične filologije in globalizacija". Primerjalna književnost 41.2 (2018): 201-214. 


\section{Comparative Literature and Classics: An Introduction to History of Scholarship and Methodology}

Keywords: comparative literature / classics / classical studies / reception studies / Brunetière, Ferdinand / Texte, Joseph / Ocvirk, Anton / Wolf, Friedrich August

The article addresses the reception of classical literature in comparative literature as a literary discipline; as well as the history of relations between comparative literature and classics or classical studies. It argues that the relationship between both disciplines is complex and dynamic, because comparative literature often neglects the study of antiquity. The influence of ancient literature and ancient literary criticism on the development of early French comparative literature is discussed. It is also suggested that Anton Ocvirk neglected antiquity's influence on the development of comparative literature. Methodological developments in classical studies are then considered and it is suggested that the methodology of comparative literature productively influenced this development. Two examples are presented: the pluralization of the term antiquity in the context of postcolonial theory and world literature studies; and the development of classical reception studies. In the conclusions, it is stressed that ancient literature and classics played an influential role in the development of comparative literature; and that comparative literature importantly influenced the development of contemporary classical studies.

1.02 Pregledni znanstveni članek / Review article

UDK 82.091

[821.124+821.14].09

DOI: https://doi.org/10.3986/pkn.v44.i2.01 